\title{
The Impact of Transformational Leadership on Organizational Identification in Kuwaiti Islamic Banks
}

\author{
Mohammad Humoud Mohammad Al-Khaldi ${ }^{1}$ \& Hani Jasa'a Irtemah ${ }^{1}$ \\ ${ }^{1}$ Faculty of Business and Finance, The World Islamic Sciences and Education University, Jordan \\ Correspondence: Mohammed Hammoud Mohammed Al-Khalidi, Faculty of Business and Finance, The World \\ Islamic Sciences and Education University, Jordan.
}

Received: May 25, 2020

doi:10.5539/mas.v14n7p111
Accepted: June 24, 2020

Online Published: June 25, 2020

\begin{abstract}
This study aimed to identify the impact of transformational leadership on organizational identification in Kuwaiti Islamic banks. The study population consists of the administrators of the five Kuwaiti Islamic banks and a random sample of 200 administrators was withdrawn to distribute the study questionnaire to them.

It is found that each of the transformational leadership dimensions is applied in Kuwaiti Islamic banks, and the dimension of Intellectual Simulation is more applied than other dimensions of transformational leadership. The study also found that Individual considerations is the most transformational dimension of leadership affecting organizational identification.

The researcher recommends the attention to the delegation of powers to employees in the executive departments in order to enhance their response to decisions related to their work, and the need for the management of the company to satisfy the needs and desires of its employees.
\end{abstract}

Keywords: transformational leadership, ideal effect, inspirational stimulation, intellectual simulation, individual considerations, organizational identification

\section{Introduction}

The human element is an important and vital factor in the effective, efficient and easy functioning of organizations, the efficiency and capacity of individuals is important in achieving the organization's objectives, the organization's success depends on hard work, loyalty and inclusion of managers and decision-makers, and staff management relies heavily on the quality of leadership held by the organizations. Leadership is a link that enables people to work together. organizations are now more concerned about understanding, developing and improving their leadership, and leaders who want to influence individuals positively must change the leadership pattern from authoritarian to more modern. (Naguib \& Naem, 2018)

New leaders adopt trends that support workers, provide them with vision, inspire hope, encourage creativity, and expand communication with individual considerations. All these factors are key features of the transformational leadership pattern that strengthens the organization and increases belonging to the work. (Eduardo \& Lacap, 2018)

Various economic sectors are experiencing various crises as a result of various political, economic, technological and natural circumstances, which make it necessary to contribute to crisis management in organizations, including non-traditional leadership patterns such as transformational leadership, which is concerned with communicating the organization's message to employees clearly and encouraging them to implement them ethically and promoting respect among both the manager and the employee(Sharma \& Singh, 2017).

The success of organizations is linked to the leader who is the backbone of the organization, and it is his responsibility to achieve the set of objectives, and a high degree of competence and effectiveness in guiding and developing the organization's course and performance, as it significantly affects the behavior and staff performance.

The nature of the work in the banks requires that the employee be heavily integrated with the bank in which he works, and his personal objectives are in line with those of the Bank within the concept of organizational 
Identification, which contributes to the achievement of the organization's objectives and improves its performance.

The importance of this study is highlighted in the fact that it is a scientific addition specialized in the field of Islamic banks in particular, where it will contribute to the provision of the Arab Scientific Library in general and Kuwait in particular a study that highlights the symmetry of the organizers under the transformational leadership.

The problem of the study is highlighted by the volatility of regulators in Islamic banks in Kuwait, and the researcher has compiled a set of opinions highlighting the need for a study highlighting the organizational identification in Islamic banks, and attention to the extent to which the employee is integrated into the bank in which he works within the concept of organizational identification. The problem of the study is also manifested in the lack of previous studies on the subject of the study, which deal with the impact of transformational leadership on organizational identification in Kuwaiti Islamic banks.

\section{Literature Review}

\subsection{Transformational Leadership}

Transformational leadership is defined as "a leadership style that inspires followers to transcend and transform personal benefit for the benefit of the organization and is able to influence the interests of the affiliates, as well as the ability of the leader to inspire employees to move beyond their personal interests towards the company's interests" (Shibru, 2011).

Murphy (2005) defines transformational leadership as "the ability of a leader to clearly convey the mission and vision of the organization to subordinates and to engage in high ethical behaviors to motivate them and build bonds of trust and respect between the two parties in order to achieve the organization's goals." Northouse(2013) defined it as "the ability of a leader to convince subordinates to change for the better, improve and develop, and the transformational leadership is to assess the performance of subordinates and motivate them to improve their performance and meet their desires and needs, and to inform them of the importance of their participation in achieving the goals of the organization."

Hawi, Hashem and Alkhodary (2015) considered transformational leadership as "the leader's ability to motivate and inspire others with his/ her outstanding talents, looking to his employee's needs, share values and ideas and motivate them by expressing confidence and being optimistic to the future vision".

According to Rafferty and Griffin (2004), transformational leadership means that a leader uses the elements of gravity and personal attributes to raise individuals' expectations and transform them into patterns of high-level performance.

Transformational leadership, as in other leadership patterns, is based on clear foundations through which the features and characteristics of that leadership are defined, and in this study will address four main dimensions of transformational leadership:

\subsubsection{Ideal Effect}

Ideal effect can be defined as "the ability of a leader to gain the trust, respect and appreciation of followers, and to be regarded as a role model and a good role model" (Barbuto, 2006).

\subsubsection{Inspirational Stimulation}

Inspirational stimulation is defined as "a leader who sets out a clear vision for the future, works to convince and work towards it, and to define a common vision between him self-employed and employees using such symbols and mental image" (Northouse, 2013).

\subsubsection{Intellectual Simulation}

Intellectual Simulation is defined as "the leader's ability to lead his followers and his desire to make them address the various kinds of problems facing the organization using new methods" (Nguyen \& Mohamed, 2011).

\subsubsection{Individual Considerations}

A set of behaviors through which the leader can give personal attention to each subordinate and identify his needs and desires while taking into account the differences between subordinates when satisfying those needs. (Yulk, 2006)

\subsection{Organizational Identification}

Organizational Identification has received increasing attention as an important area of investigation in applied psychology. Sociologists point out that identity issues at all levels are prominent in current contexts 
characterized by fragmentation, downtime and economic crisis. (Piccoli, Callea, Urbini, Chirumbolo, Ingusci, \& Witte, 2017)

Riketta (2005) points out that all different definitions of the Organizational Identification in literature indicate that the individual feels part of the organization, the understanding of organizational values and/or a sense of pride in its membership.

With regard to the overlap between both the concept of Organizational Identification and the concept of Organizational Identification, it can be said that the Organizational Identification is a component of the Organizational Identification. As Organizational Identification differs from emotional behaviors (e.g. commitment, consent) or other behaviors (e.g. individual efforts on behalf of the organization), these behaviors +9 are potential outcomes of Organizational Identification, as one can register a high level of commitment without realizing the common destiny with the organization. An individual who has a commitment to values and objectives can be transferred to a similar organization or even to a competing organization through motivation, but even if the individual is systematically identical even if transferred to another organization, he or she will feel lost because of his exit. (Bashkali, 2017)

Tuna, Bacaksiz and Seren (2018) showed a positive relationship between organizational identification and employee performance. The individual's sense of being part of the organization, the assimilation of organizational values and/or the sense of pride in his membership is reflected in different aspects of his performance (Riketta, 2005).

The importance of organizational identification is highlighted by the following: (Rashid, 2003)

1. To present the public interest over the personal interest when evaluating alternatives and making decisions about the organization.

2. Work to increase commitment, regularity, performance, high motivation and reduce conflict and contradiction.

3. Improving the organization's position in society and highlighting its competitive advantage compared to its competition from other organizations.

4. Accept the employees represented by the organization for development and change easily, because they are convinced that it is in the public interest.

5. Increase the degree of loyalty and activate cooperation between the employees of the organization.

6. The psychological association between the workers as a team, that their fate and destiny are the same and that success or failure affects them all.

7. Employees are satisfied with the job and the conviction of work, thereby improving their performance and increasing their effectiveness and efficiency in the performance of their duties.

8. Adopt ing the bright and positive image of the organization and believing in it and highlighting all aspects related to this aspect.

\section{Hypothesis}

1. There is an impact of transformational leadership on organizational identification in Kuwaiti Islamic banks

2. There is an impact of Ideal effect on organizational identification in Kuwaiti Islamic banks

3. There is an impact of Inspirational stimulation on organizational identification in Kuwaiti Islamic banks

4. There is an impact of Intellectual Simulation on organizational identification in Kuwaiti Islamic banks

5. There is an impact of Individual considerations on organizational identification in Kuwaiti Islamic banks

\section{Population and Sample}

The study population consists of the administrators of the five Kuwaiti Islamic banks (United National Bank, Bobyan Bank, Kuwait Finance House, Kuwait Bank, Warba Bank) and a random sample of 200 administrators was withdrawn to distribute the study questionnaire to them.

\section{Data Collection Methods}

The researcher adopted two types of data collection methods:

\subsection{Preliminary Data}

These are the data on which the researcher is based to achieve the objectives of the study and are collected by the questionnaire that was distributed to the individuals of the sample. 


\subsection{Secondary Data}

Secondary data sources were used from books, references, periodicals, journals and related previous studies.

\section{Reliability Test}

The Cronbach Alpha test was used to test the stability of the measuring instrument, and according to the following table, the alpha value per variable was found to be higher than the acceptable ratio of 0.60 , reflecting the stability of the study resolution. (Sekaran, 2006)

\section{Analysis}

\subsection{Sample Characteristics}

Frequency and percentages were computed for sample's characteristics, it is found that males were (147) subjects that is $(73.5 \%)$, females were (53) subjects, that is (26.5\%) percent. Also, it is found that $66 \%$ of the sample has more than 15 years as experience in Kuwaiti Islamic banks, followed with (37.5\%) percent of (40- to less than 50 years). The educational level for (45\%) of the sample is bachelor degree.

\subsection{Descriptive Analysis}

Mean and standard deviation were used to describe attitudes toward following variables:

Table 1. Descriptive Statistics

\begin{tabular}{cccccc}
\hline & $\mathrm{N}$ & Minimum & Maximum & Mean & Std. Deviation \\
\hline Ideal effect & 200 & 1.00 & 5.00 & 3.7400 & .90248 \\
Inspirational stimulation & 200 & 1.00 & 5.00 & 3.8770 & 1.10689 \\
Intellectual Simulation & 200 & 1.00 & 5.00 & 3.9370 & 1.32082 \\
Individual considerations & 200 & 1.00 & 5.00 & 3.6310 & .92863 \\
Organizational Identification & 200 & 1.00 & 5.00 & 3.7890 & 1.13690 \\
\hline
\end{tabular}

Table 1 shows that there are positive attitudes toward each variable because their means are greater than the mean of the scale (3). The highest mean (3.937) reflects highest level of acceptance toward Intellectual Simulation dimension whereas, the mean (3.3610) reflects lowest level of acceptance toward Individual considerations dimension.

\subsection{Hypothesis Testing}

7.3.1 There is an impact of transformational leadership on organizational identification in Kuwaiti Islamic banks.

Table 2. H1 testing

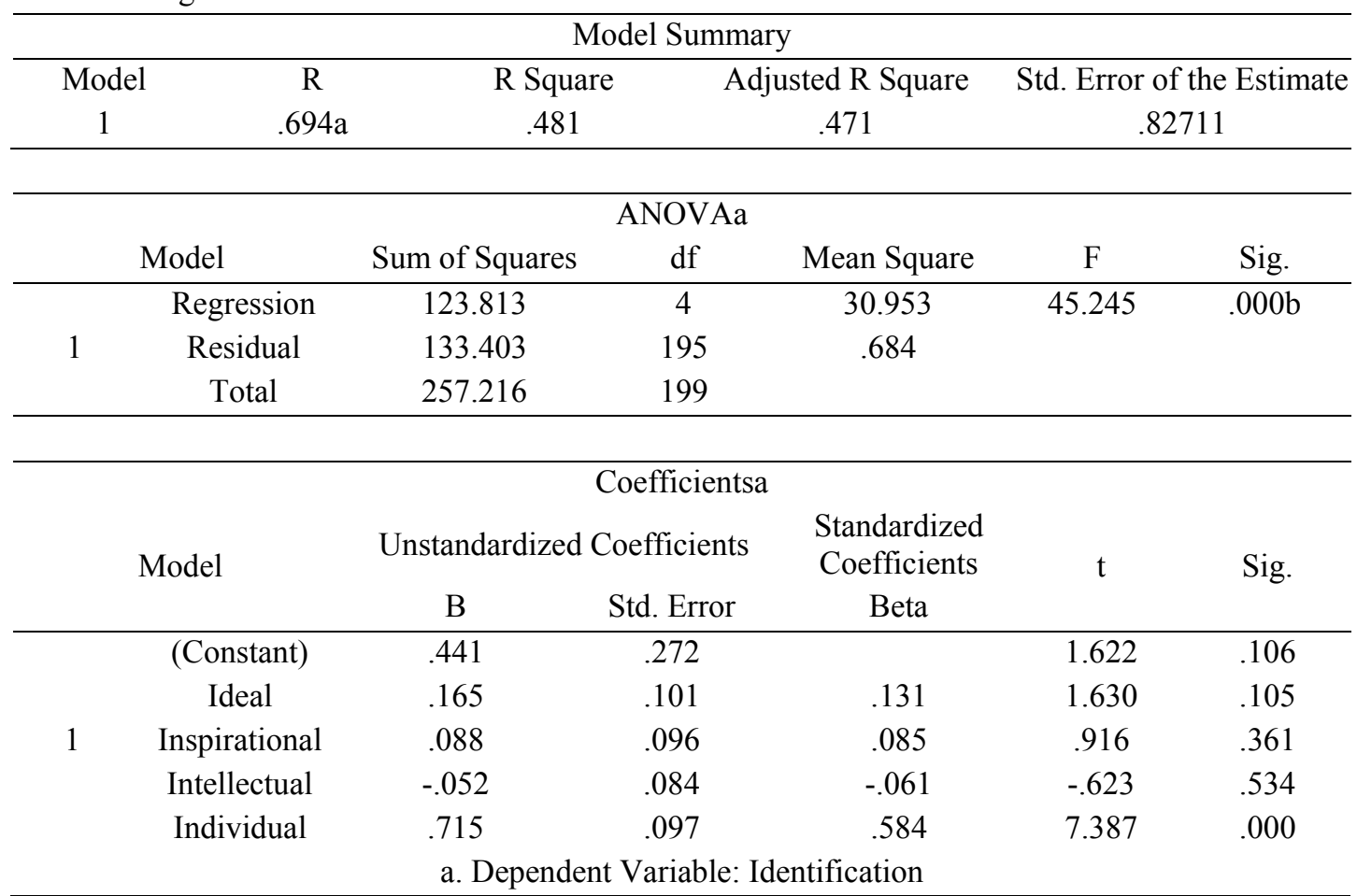


Multiple regression is used to test above hypothesis. Table 2 shows that $F$ value $=42.245$ is significant at 0.05 level. Also, $\mathrm{r}=0.694$ reflects high level of correlation and $48.1 \%$ of the variance in organizational identification is explained by the independent variables.

That means there is an impact of transformational leadership on organizational identification in Kuwaiti Islamic banks.

7.3.2 There is an impact of Ideal effect on organizational identification in Kuwaiti Islamic banks.

Table 3. H2 testing

Model Summary

\begin{tabular}{ccccc} 
Model & R & R Square & $\begin{array}{c}\text { Adjusted R } \\
\text { Square }\end{array}$ & $\begin{array}{c}\text { Std. Error of the } \\
\text { Estimate }\end{array}$ \\
\hline 1 & $.543 \mathrm{a}$ & .295 & .291 & .95725
\end{tabular}

\begin{tabular}{ccccccc}
\hline & & \multicolumn{3}{c}{ ANOVAa } & & \\
& Model & Sum of Squares & df & Mean Square & F & Sig. \\
\hline \multirow{3}{*}{1} & Regression & 75.783 & 1 & 75.783 & 82.702 & $.000 \mathrm{~b}$ \\
& Residual & 181.433 & 198 & .916 & & \\
& Total & 257.216 & 199 & & \\
\hline
\end{tabular}

\begin{tabular}{|c|c|c|c|c|c|}
\hline \multirow{3}{*}{ Model } & \multicolumn{3}{|c|}{ Coefficientsa } & \multirow{3}{*}{$\mathrm{t}$} & \multirow{3}{*}{ Sig. } \\
\hline & \multicolumn{2}{|c|}{ Unstandardized Coefficients } & \multirow{2}{*}{$\begin{array}{c}\text { Standardized } \\
\text { Coefficients } \\
\text { Beta }\end{array}$} & & \\
\hline & B & Std. Error & & & \\
\hline (Constant) & 1.232 & .289 & & 4.258 & .000 \\
\hline Ideal & .684 & .075 & .543 & 9.094 & .000 \\
\hline
\end{tabular}

a. Dependent Variable: Identification

Linear regression is used to test above hypothesis. Table 3 shows that $\mathrm{F}$ value $=82.702$ is significant at 0.05 level. Also, $r=0.543$ reflects medium level of correlation and $29.5 \%$ of the variance in organizational identification is explained by the independent variable.

That means there is an impact of Ideal effect on organizational identification in Kuwaiti Islamic banks. 
7.3.3 There is an impact of Inspirational stimulation on organizational identification in Kuwaiti Islamic banks.

Table 4. H3 testing

\begin{tabular}{ccccc}
\hline Model & R & R Square & $\begin{array}{c}\text { Adjusted R } \\
\text { Square }\end{array}$ & $\begin{array}{c}\text { Std. Error of the } \\
\text { Estimate }\end{array}$ \\
\hline 1 & $.498 \mathrm{a}$ & .248 & .244 & .98844 \\
& \multicolumn{4}{c}{ a. Predictors: (Constant), Inspirational } \\
\hline
\end{tabular}

\begin{tabular}{|c|c|c|c|c|c|c|}
\hline \multicolumn{7}{|c|}{ ANOVAa } \\
\hline & Model & Sum of Squares & df & Mean Square & $\mathrm{F}$ & Sig. \\
\hline \multirow{3}{*}{1} & Regression & 63.768 & 1 & 63.768 & 65.268 & $.000 \mathrm{~b}$ \\
\hline & Residual & 193.448 & 198 & .977 & & \\
\hline & Total & 257.216 & 199 & & & \\
\hline
\end{tabular}

a. Dependent Variable: Identification

b. Predictors: (Constant), Inspirational

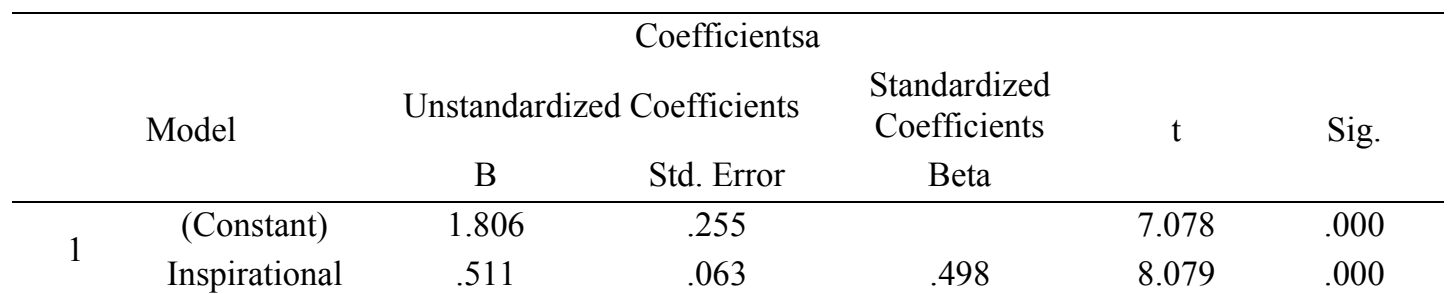

a. Dependent Variable: Identification

Linear regression is used to test above hypothesis. Table 4 shows that $\mathrm{F}$ value $=65.268$ is significant at 0.05 level. Also, $r=0.498$ reflects medium level of correlation and $24.8 \%$ of the variance in organizational identification is explained by the independent variable.

That means there is an impact of Inspirational stimulation on organizational identification in Kuwaiti Islamic banks.

7.3.4 There is an impact of Intellectual Simulation on organizational identification in Kuwaiti Islamic banks.

Table 5. H4 testing

\section{Model Summary}

\begin{tabular}{ccccc} 
Model & $\mathrm{R}$ & R Square & $\begin{array}{c}\text { Adjusted R } \\
\text { Square }\end{array}$ & $\begin{array}{c}\text { Std. Error of the } \\
\text { Estimate }\end{array}$ \\
\hline 1 & $.513 \mathrm{a}$ & .264 & .260 & .97808
\end{tabular}

a. Predictors: (Constant), Intellectual

\begin{tabular}{|c|c|c|c|c|c|c|}
\hline \multicolumn{7}{|c|}{ ANOVAa } \\
\hline & Model & Sum of Squares & $\mathrm{df}$ & Mean Square & $\mathrm{F}$ & Sig. \\
\hline \multirow{3}{*}{1} & Regression & 67.801 & 1 & 67.801 & 70.874 & $.000 \mathrm{~b}$ \\
\hline & Residual & 189.415 & 198 & .957 & & \\
\hline & Total & 257.216 & 199 & & & \\
\hline \multicolumn{7}{|c|}{ Coefficientsa } \\
\hline & \multirow[t]{2}{*}{ Model } & \multicolumn{2}{|c|}{ Unstandardized Coefficients } & $\begin{array}{c}\text { Standardized } \\
\text { Coefficients }\end{array}$ & $\mathrm{t}$ & Sig. \\
\hline & & $\mathrm{B}$ & Std. Error & Beta & & \\
\hline \multirow{2}{*}{1} & (Constant) & 2.049 & .218 & & 9.403 & .000 \\
\hline & Intellectual & .442 & .052 & .513 & 8.419 & .000 \\
\hline
\end{tabular}


Linear regression is used to test above hypothesis. Table 5 shows that $\mathrm{F}$ value $=70.874$ is significant at 0.05 level. Also, $r=0.513$ reflects medium level of correlation and $26.4 \%$ of the variance in organizational identification is explained by the independent variable.

That means there is an impact of Intellectual Simulation on organizational identification in Kuwaiti Islamic banks.

7.3.5 There is an impact of Individual considerations on organizational identification in Kuwaiti Islamic banks

Table 6. H5 testing

Model Summary

\begin{tabular}{ccccc} 
Model & $\mathrm{R}$ & R Square & $\begin{array}{c}\text { Adjusted R } \\
\text { Square }\end{array}$ & $\begin{array}{c}\text { Std. Error of the } \\
\text { Estimate }\end{array}$ \\
\hline 1 & $.683 \mathrm{a}$ & .466 & .464 & .83265 \\
\multicolumn{4}{c}{ a. Predictors: (Constant), Individual } \\
\hline
\end{tabular}

\begin{tabular}{ccccccc}
\hline \multicolumn{1}{c}{ Model } & Sum of Squares & df & Mean Square & F & Sig. \\
\hline \multirow{3}{*}{1} & Regression & 119.943 & 1 & 119.943 & 173.003 & $.000 \mathrm{~b}$ \\
& Residual & 137.273 & 198 & .693 & & \\
& Total & 257.216 & 199 & & \\
& \multicolumn{5}{c}{ a. Dependent Variable: Identification } \\
& b. Predictors: (Constant), Individual \\
\hline
\end{tabular}

\begin{tabular}{|c|c|c|c|c|c|c|}
\hline \multicolumn{7}{|c|}{ Coefficientsa } \\
\hline & \multirow{2}{*}{ Model } & \multicolumn{2}{|c|}{ Unstandardized Coefficients } & \multirow{2}{*}{$\begin{array}{c}\text { Standardized } \\
\text { Coefficients } \\
\text { Beta }\end{array}$} & \multirow{2}{*}{$\mathrm{t}$} & \multirow{2}{*}{ Sig. } \\
\hline & & B & Std. Error & & & \\
\hline \multirow{2}{*}{1} & (Constant) & .753 & .238 & & 3.163 & .002 \\
\hline & Individual & .836 & .064 & 683 & 13.153 & .000 \\
\hline
\end{tabular}

Linear regression is used to test above hypothesis. Table (6) shows that $\mathrm{F}$ value $=173.003$ is significant at 0.05 level. Also, $\mathrm{r}=0.683$ reflects high level of correlation and $46.6 \%$ of the variance in organizational identification is explained by the independent variable.

That means there is an impact of Individual considerations on organizational identification in Kuwaiti Islamic banks.

\section{Conclusion}

This study aimed to identify the impact of transformational leadership on organizational identification in Kuwaiti Islamic banks.

It is clear from the review of the dimensions of transformational leadership that each of these dimensions is applied in Kuwaiti Islamic banks, and the dimension of Intellectual Simulation is more applied than other dimensions of transformational leadership, where the transformational leader provokes the thinking of subordinates, encourages innovation, rationality and creativity in solving business problems, and encourages their spirit of innovation and acceptance of their ideas even if they conflict with his ideas, and does not allow public criticism in the event of failure, as the leader stimulates the transformational subordinates. by discussing their ideas and the problems they face.

The study also found that Individual considerations is the most transformational dimension of leadership affecting organizational identification, and the dimension of individual considerations reflects the behaviors shown by the leader in order to reach the satisfaction of subordinates by providing support, guidance and 
attention to the needs and desires of subordinates, as provided by the leader, Channels of feedback and linking the needs of subordinates to the vision of the organization, and they encourage subordinates to think creatively, where the transformational leader considers each of the subordinates a special person and has his own characteristic, instead of being considered part of the group, and therefore he works as a subordinate guide, he understands his problems, listens to his concerns, and recognizes the strengths and weaknesses of subordinates, thus promoting the building of a relationship based on respect and public dissemination of the individual's achievements, thus generating a strong will for development and creativity.

Hence, the researcher recommends the attention to the delegation of powers to employees in the executive departments in order to enhance their response to decisions related to their work, and the need for the management of the company to satisfy the needs and desires of its employees. Also it is needed to have an interest in encouraging employees to engage constructively among themselves, the need to work on the use of positive motivation of its employees through the development of the system of incentives and compensation sought for employees, and that the management care about the feelings of its employees to encourage them to be loyal and first to the bank and reflect positively on their organizational identification.

\section{References}

Barbuto, J., \& Burbach, M. (2006). The emotional intelligence of transformational leaders: A field study of elected officials. The Journal of Social Psychology, 146(1), 51-64. https://doi.org/10.3200/SOCP.146.1.51-64

Bashkali, Mahmoud. (2017). Diagnosing the Relationship between Organizational Identification and the Causes of Organizational Silence: A Survey Study of Teaching Staffs in a Sample of the Faculties of the University of Duhok. Journal of Human Sciences of Zakho University, 5(3), 796-813.

Eduardo, M., \& Lacap, J. (2018). The Role of Transformational Leadership on Employees, Intention to Quit. PREO Journal of Business and Management, 1(1), 39-53.

Hawi, R., Hashem, T., \& Alkhodary, D. (2015). The Relationship between Transformational Leadership and Organizational Performance in Jordan Universities from Middle Managers Perspective. IJMBS, 5(4),39-46.

Murphy, L. (2005). Transformational Leadership: A Cascading Chain Reaction. Journal of Nursing Management, 13(2),128-136. https://doi.org/10.1111/j.1365-2934.2005.00458.x

Naguib, H., \& Abou Naem, A. (2018). The impact of Transformational leadership on the organizational innovation. The International Journal of Social Sciences and Humanities Invention, Cairo, Egypt, 5(1), 4337-4343. https://doi.org/10.18535/ijsshi/v5i1.15

Nguyen, H., \& Mohamed, S. (2011). Leadership behaviors, organizational culture and knowledge management practices: An empirical investigation. Journal of Management Development, 30(2), 206-221. https://doi.org/10.1108/02621711111105786

Northouse, P. (2013). Leadership theory and practice, 6th edition, Thousand Oaks, CA: Sage publication.

Piccoli, B., Callea, A., Urbini, F., Chirumbolo, A., Ingusci, E., \& Witte, H. (2017). Job insecurity and performance: the mediating role of organizational identification. Personnel Review, 46(8), 1508-1522. https://doi.org/10.1108/PR-05-2016-0120

Rashid, M. (2003). Organizational identity and Organizational Identification: an analysis of the concept and behavioral dimensions of its applications, issued by the Research Center of the Faculty of Administrative Sciences. Riyadh: Scientific Publishing House and Printing Presses.

Riketta, M. (2005). Organizational identification: A meta-analysis. Journal of Vocational Behavior, 66, 358-384. https://doi.org/10.1016/j.jvb.2004.05.005

Sekaran, U. (2006). Research methods for business: A skill building approach. New York, NY.: John Wiley \& Sons.

Sharma, R., \& Singh, S. (2017). Transformational Leadership Style and Self-Efficacy among Teaching Professionals. The International Journal of Indian Psychology, 4(2), 141.

Shibru, B., \& Darshan, G.M. (2011). Transformational Leadership and its Relationship with Subordinate Satisfaction with the Leader (The Case of Leather Industry in Ethiopia). Interdisciplinary Journal of contemporary research in Business, 3(5), 686-697. 
Sim, Y., \& Lee, E. (2018). Perceived underqualification and job attitudes: the role of transformational leadership. $\begin{array}{llll}\text { Leadership \& Organization Development Journal, 39(8), 962-974. } & \text { \& }\end{array}$ https://doi.org/10.1108/LODJ-03-2018-0127

Tuna, R., Bacaksız, F., \& Seren, A. (2018). The Effects of Organizational Identification and Organizational Cynicism on Employee Performance Among Nurses. International Journal of Caring Sciences, 2(3), 707-714.

\section{Copyrights}

Copyright for this article is retained by the author(s), with first publication rights granted to the journal.

This is an open-access article distributed under the terms and conditions of the Creative Commons Attribution license (http://creativecommons.org/licenses/by/3.0/). 